\title{
Isolated Renal Hydatid Cyst: CT Imaging Findings
}

\author{
İole Renal Kist Hidatik: BT Görüntüleme Bulguları
}

\section{Canan Altay, Ișıl Başara, Mustafa Seçil}

Dokuz Eylül University Faculty of Medicine, Department of Radiology, Izmir, Turkey

A 52-year-old male presented to the emergency department with a 5-month history of episodic left flank pain. The physical examination and laboratory tests suggested stone disease. Chest radiography and the neurological examination were unremarkable.

Ultrasonography revealed a multiloculated cystic lesion in the left kidney. Contrast-enhanced computed tomography (CT) revealed a $7 \mathrm{~cm}$ diameter multiloculated cyst arising from the left kidney with a thick capsule with well-defined borders, containing multiple, peripherally located, tiny daughter cysts (Figure 1a,b). This appearance was compatible with a WHO type 2 A hydatid cyst. No additional cystic lesions were found on abdominopelvic CT or chest X-ray. He underwent surgery and the diagnosis of hydatid disease was made histopathologically.

Hydatid disease is a common zoonosis of ruminants in which humans are an intermediate host. The major radiological findings of hydatid disease are unilocular, multilocular, or calcified cysts in located anywhere in the body (1). The sites most commonly affected by hydatid cysts are the liver, lungs, and central nervous system (2). Renal hydatid cysts are rare and occur in 2-3\% of all cases (3).

Von Sinner et al. developed a widely accepted classification of hydatid cysts based on their radiological appearance, describing four types of hydatid cyst $(2,4)$; type 1 cysts are unilocular, well-defined, homogenous cysts without septations; type 2 cysts contain numerous daughter cysts inside the mother cyst and are subdivided into type 2A (round daughter cysts located peripherally), type 2B (larger, irregular daughter cysts and thick internal septations in the mother cyst), and type 2C (high-attenuated round or oval lesions with internal calcifications)-type 2 cysts may show capsular calcification; type 3 cysts are dead lesions that are calcified entirely; and type 4 cysts are lesions complicated by rupture or superinfection. Rupture is seen in 50-90\% of all cases (2).

The standard treatment for hydatid disease is surgical resection combined with medical treatment. Percutaneous drainage is used widely to treat hydatid cysts (5).

In conclusion, a renal hydatid cyst is a rare renal cystic lesion. CT is an important radiological method that can reveal the correct diagnosis.

Key Words: Hydatid cyst, CT, renal cyst
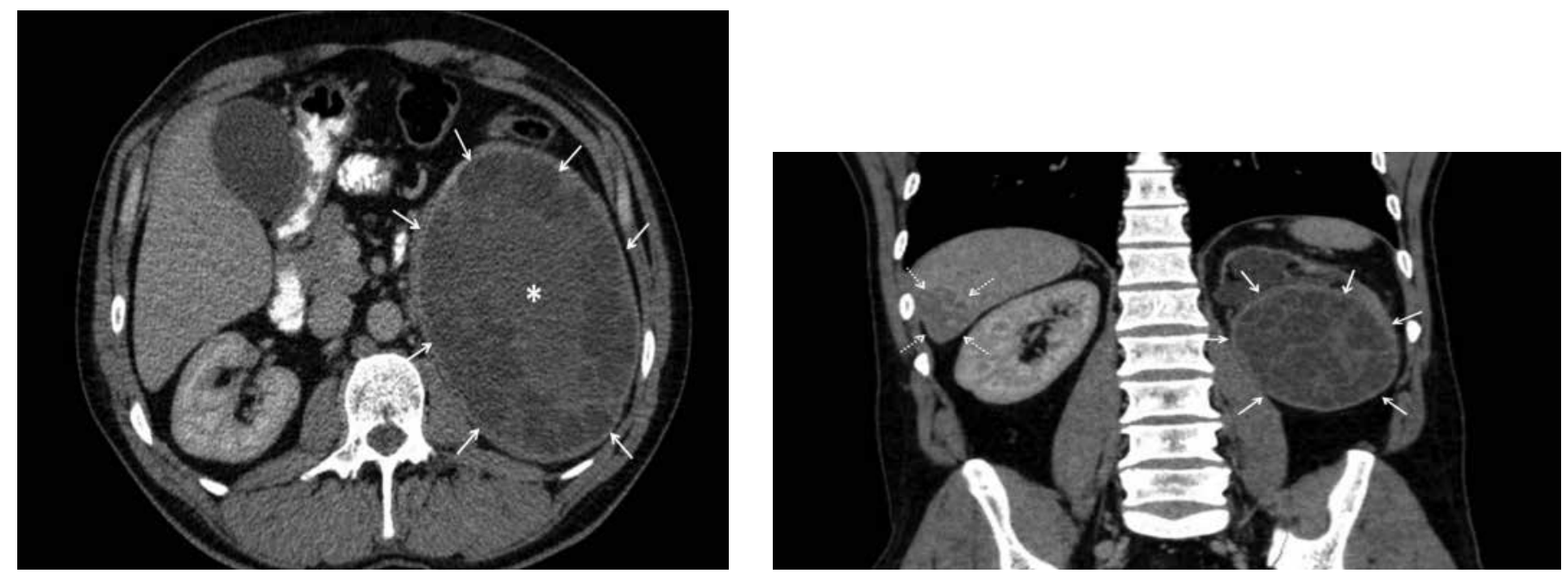

Axial (a) and coronal reformatted (b) CT scans show a hypoattenuating mass with well-defined borders in the lower pole of the left kidney. Peripherally located and round shaped daughter cysts are seen within the lesion (white arrows). The central portion of lesion is hyperattenuating due to content of mother cyst (asterisk). An incidental hemangioma is seen in right lobe of liver (stippled white arrows).

\section{Correspondence}

Canan Altay MD, Dokuz Eylül University Faculty of Medicine, Department of Radiology, İzmir, Turkey

Phone: +902324125901 E-mail: cananaltay@yahoo.com 


\section{References}

1. Polat P, Kantarci M, Alper F, Suma S, Koruyucu MB, Okur A. Hydatid disease from head to toe. Radiographics 2003; 23:475-494; quiz 536-7.

2. Pedrosa I, Saiz A, Arrazola J, Ferreirós J, Pedrosa CS. Hydatid disease: radiologic and pathologic features and complications. Radiographics 2000;20:795-817.

3. Ishimitsu DN, Saouaf R, Kallman C, Balzer BL. Best cases from the AFIP. Renal hydatid disease. Radiographics 2010;30:334-337.

4. Von Sinner W, te Strake L, Clark D, Sharif H. MR imaging of HD. AJR Am J Roentgenol 1991;157:741-745.

5. Karaman B, Battal B, Ustunsoz B, Ugurel MS. Percutaneous treatment of a primary pancreatic hydatid cyst using a catheterization technique. Korean J Radiol 2012;13:232-236.

5. Karaman B, Battal B, Ustunsöz B, Uğurel MS. Percutaneous treatment of a primary pancreatic hydatid cyst using a catheterization technique. Korean J Radiol 2012; 13:232-236. 